\title{
Evaluation of Flow Rate, pH, Buffering Capacity, Calcium, Total Proteins and Total Antioxidant Capacity Levels of Saliva in Caries Free and Caries Active Children: An In Vivo Study
}

\author{
B. P. Preethi · Dodawad Reshma $\cdot$ Pyati Anand
}

Received: 26 November 2009/ Accepted: 7 June 2010/Published online: 14 September 2010

(C) Association of Clinical Biochemists of India 2010

\begin{abstract}
The purpose of this study was to evaluate the relationship between the physicochemical properties of saliva such as flow rate, $\mathrm{pH}$, buffering capacity, calcium level, total protein and total antioxidant levels in caries free and caries active children. The present study included one hundred and twenty healthy children who were divided into two groups; group I and group II comprising of age groups 7-10 and 11-14 years, respectively. Both the groups were then sub-divided equally according to gender. They were further divided into caries free and caries active with 15 children in each group. Unstimulated saliva was collected by suction method and flow rates were determined. The samples were then analyzed for $\mathrm{pH}$, buffering capacity, total protein, calcium and total antioxidant capacity. The data was statistically analyzed using student $t$ test (unpaired). The results revealed that when all these parameters were compared among the caries free and caries active children, flow rate, $\mathrm{pH}$, buffering capacity were slightly reduced in caries active children, but total protein and total antioxidant capacity of saliva increased significantly in caries active children and the total calcium decreased significantly in caries active children. Within the limitation of this study, we conclude that, the physicochemical properties of saliva play a major role in the development of caries.
\end{abstract}

Keywords Saliva $\cdot \mathrm{pH} \cdot$ Calcium $\cdot$ Total proteins $\cdot$ Total antioxidant capacity $\cdot$ Dental caries

B. P. Preethi $(\bowtie) \cdot$ P. Anand

Department of Biochemistry, J.J.M. Medical College Hospital,

Davangere 577004, Karnataka, India

e-mail: preethi_chidan@yahoo.co.in

D. Reshma

Department of Pedodontics, College of Dental Sciences,

Davangere, Karnataka, India

\section{Introduction}

Among the oral diseases, dental caries is the most common chronic disease of mankind [1]. It affects all people regardless of their sex, socioeconomic strata, race and age. It is also profoundly affected by other factors like oral hygiene and saliva [2].

The saliva circulating in the mouth at any given time is termed as whole saliva and it comprises of a mixture of secretions from the major and minor salivary glands and traces from the gingival crevicular fluid. Saliva definitely promotes oral health and hence lack of its secretion contributes to the disease process [3]. The saliva by constantly bathing the teeth and oral mucosa, functions as a cleansing solution, a lubricant, a buffer and an ion reservoir of calcium and phosphate which are essential for remineralization of initial carious lesions.

It has been long recognized that saliva serves as a mirror of the body's health as it contains proteins, hormones, antibodies and other molecules that are frequently measured in standard blood tests to monitor health and disease. However, unlike whole blood, saliva is easy to collect, less painful to the patient and is less infectious for the health care provider. Healthy individuals produce about a litre and a quarter of saliva per day. Nearly all analytes that are in blood are also present in saliva. Although saliva has not been used as much up to this point as a sampling media, it does have a strong potential to do the same kinds of tests that are done currently in blood [4]. As for the literature available very little has been discussed about dental caries and antioxidants.

Recently it has been claimed that the imbalances in levels of free radicals, reactive oxygen species and antioxidants in saliva may play an important role in the onset and development dental caries [5]. Hence evaluation of 
those factors in saliva that may increase the risk of individuals to dental caries, can pave way to make recommendations that will cater specifically to needs of an individual [6].

\section{Materials and Methods}

\section{Subjects}

One hundred and twenty children of age group between 7 and 14 years reporting to the Department of Pedodontics and Preventive Dentistry, Bapuji Dental College and Hospital, Davangere, were included as subjects of this study. They were divided into two groups; group I and group II comprising of age groups 7-10 and 11-14 years, respectively. Both the groups were then sub-divided according to gender with 30 children in each group. They were then further divided into caries active and caries free groups, with 15 children in each group. Salivary analysis was carried out in Biochemistry department of J.J.M. Medical College, Davangere. The study protocol was approved by the Ethics Committee of J.J.M. Medical College, Davangere. Informed consent was obtained from parent/guardian of each child.

The Inclusion and exclusion criteria used are as follows:

Inclusion criteria: (i) free from systemic or local diseases which affect salivary secretions, (ii) children should be permanent residents of Davangere city and should be consuming only municipal water, (iii) caries status was assessed according to the WHO criteria: caries active children having at least five decayed tooth surfaces; caries free children having no caries, Decayed Missing Filled Surfaces $($ DMFS $)=0$.

Exclusion criteria: (i) patients who are physically and medically compromised, (ii) patients who are on medications, and (iii) patients who have arrested carious lesions.

Stratified randomized sampling procedure was employed for the statistical analysis.

Unstimulated saliva was collected for the study. The saliva was allowed to accumulate in patient's mouth for $2 \mathrm{~min}$ and was aspirated directly from the floor of the mouth. Each sample was estimated for $\mathrm{pH}$, buffering capacity, total calcium, total protein and total antioxidant capacity.

\section{Salivary Analysis}

Estimation of Flow Rate of Saliva

The flow rate of saliva was estimated by asking children to spit into (the) preweighed plastic cylinders for $5 \mathrm{~min}$.
These plastic cylinders (containing saliva) were then weighed and the flow rate was calculated in $\mathrm{g} / \mathrm{ml}$ which is almost equivalent to $\mathrm{ml} / \mathrm{min}$ [7].

\section{Estimation of $\mathrm{pH}$ and Buffering Capacity}

$\mathrm{pH}$ of saliva was measured by using manual $\mathrm{pH}$ meter and buffering capacity of saliva by Ericsson method 1959 . $0.5 \mathrm{ml}$ of saliva was added to $1.5 \mathrm{ml}$ of $5 \mathrm{mmol} / \mathrm{l} \mathrm{HCl}$. The mixture was vigorously shaken and then centrifuged for 1 min and allowed to stand for $10 \mathrm{~min}$ when the final $\mathrm{pH}$ was measured by using manual $\mathrm{pH}$ meter [8].

\section{Estimation of Total Antioxidant Capacity of Saliva}

Total salivary antioxidant capacity levels were estimated using a spectrophotometer [8]. Principle: A standardized solution of Fe EDTA complex reacts with hydrogen peroxide by a Fenton type reaction leading to the formation of hydroxyl radicals. These reactive oxygen species degrade benzoate, resulting in release of TBARS. Antioxidants from the added human sample (saliva) cause suppression of production of TBARS. This reaction can be measured spectrophotometrically and inhibition of color development as Total antioxidant capacity.

\section{Estimation of Total Calcium and Total Protein of Saliva}

Estimation of total protein and calcium was done by autoanalyzer which works on the principle of atomic absorption spectrophotometer [9]. Total calcium and total protein was estimated). The estimation was done by using 'Human diagnostic kit' (Germany).

Statistical Analysis

Results are presented as mean \pm standard deviation values. Student $t$ test was used to compare the mean values between caries free and caries active groups. $P$ value of 0.05 or less was considered for standard significance.

\section{Results and Discussion}

Under resting conditions without the exogenous stimulation that is linked with feeding, there is a slow flow of saliva which keeps the mouth moist and lubricates the mucous membrane. This unstimulated flow, is what is secreted by the salivary glands the majority of the time. Unstimulated saliva is essential for the health and well being of the oral cavity and also bestows a strong protective effect to the oral cavity, against dental caries [10]. 
On observation flow rate, $\mathrm{pH}$, buffering capacity and calcium are slightly decreased in caries active children compared to caries free children however, the difference was not found to be statistical significant (Table 1).

In general, higher the flow rate, faster the clearance and higher the buffering capacity and thus lesser microbial attacks. Parallel results were seen in the studies conducted by Browne et al. and Scully where they showed that dental caries is probably the most common consequence of hypo salivation. In contrast to the above, the studies conducted by Birkhed, Heintze and Russell et al. reported that there was no correlation between salivary secretion rate and caries activity [11].

In relation to $\mathrm{pH}$, the outcome of the present study showed that in caries active children $\mathrm{pH}$ ranged from 6.20 to 7.90. It has been well documented that the dissolution of enamel occurs when the $\mathrm{pH}$ falls below critical $\mathrm{pH}$, i.e. 5.5, so the values obtained in the study are not adequate to cause demineralization of inorganic substance of the tooth.

The study showed that $\mathrm{pH}$ and buffering capacity had a weak correlation with caries activity. Hence it can be speculated that other factors like micro flora, diet and retention of food might have dominated the buffering capacity to initiate caries, which is a multifactorial disease [12]. Similar results were seen in a study conducted by Tuhunoglu who showed no correlation between $\mathrm{pH}$ values and caries activity regardless of the age and gender. They were dependent upon individual and environmental variations. The results of the current study was in contrast to the study conducted by Ericsson which showed that salivary buffering capacity has a negative relationship with caries incidence [13].

The mean level of calcium is decreased in caries active children when compared to caries free children and is statistically significant. The decrease in the caries experience in children with high calcium concentration in saliva is attributed to the process of remineralization of the incipient caries lesions. The saliva which is supersaturated with calcium and phosphate acts as a reservoir for these essential ions. In such a conducive environment the process of remineralization overrides demineralization.

Further as shown in Table 1, total proteins increased in caries active children as compared to caries free children and is statistically significant. Saliva contains many biological systems known to be involved in soft tissue repair and many antibacterial components including lysozyme, lactoferrin and salivary peroxidase all of these are protein in nature. Human saliva contains a complex peroxidase system, the major components of which include different forms of lactoperoxidase secreted by salivary glands and myeloperroxidase from polymorphonuclear neutrophils. It has been suggested that one of the most important function of salivary peroxidase is the control of oral bacteria that form dental plaque, to imbalance in etiology which lead to dental caries [14].

Table 1 Salivary parameters in caries active and caries free children

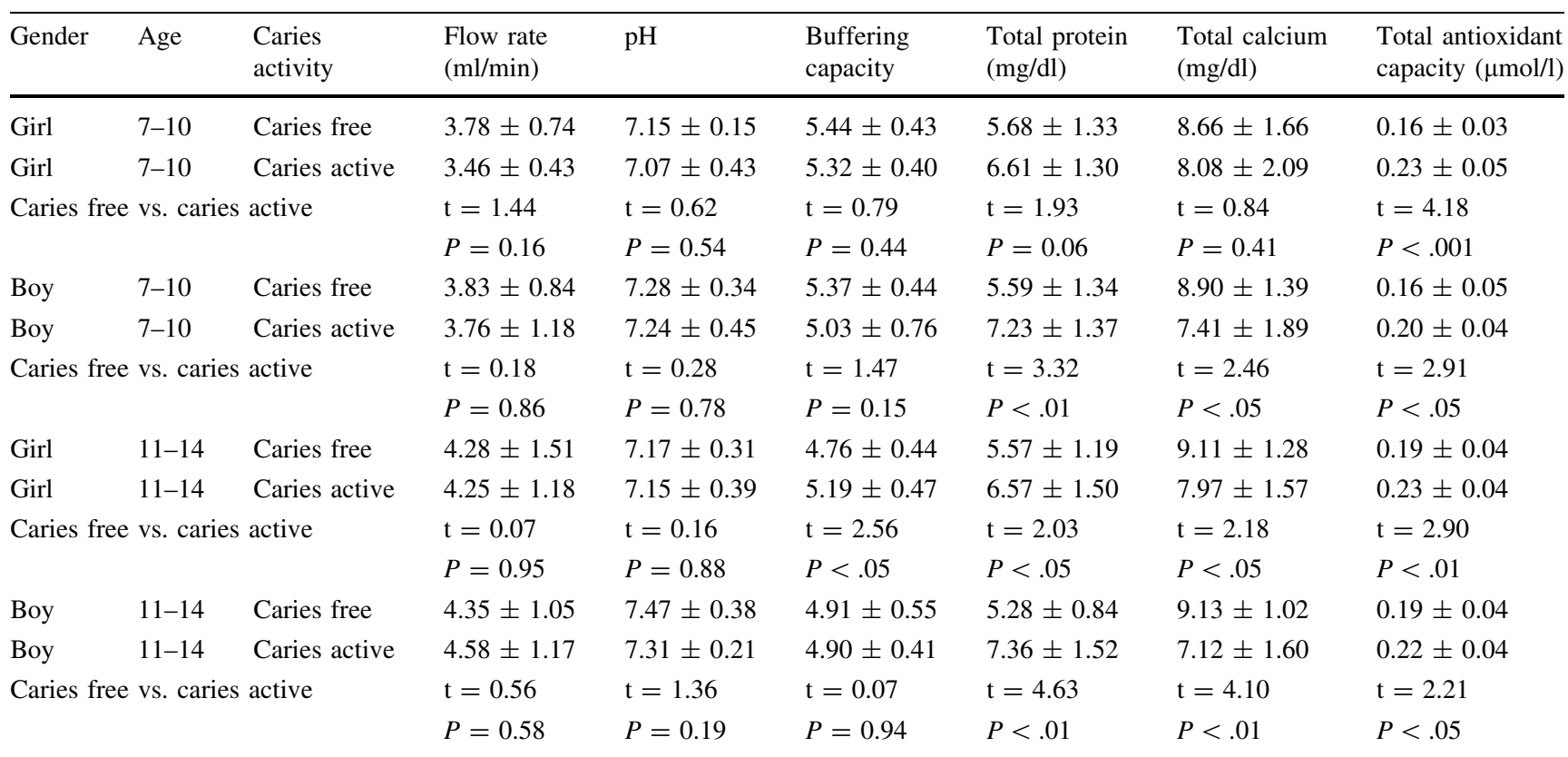

Unpaired $t$ test

$P<0.05$, significant

$P>0.05$, not significant 
Total anti-oxidant capacity is increased in caries active children when compared to caries free children and is statistically significant. Saliva may contribute a first line of defence against free radical mediated oxidative stress, since the process of mastication promotes a variety of such reactions including lipid peroxidation [14]. In our study, we have evaluated total antioxidant capacity in contrast to other reported literature available where individual antioxidant have been evaluated. We took total antioxidant capacity in our study as it is suggested that free radical/ reactive oxygen species and antioxidant system appear to act in concert rather than alone, and measurement of any individual antioxidant may be less representative of whole antioxidant status. Moreover, the number of different antioxidants makes it difficult and also expensive to measure each of them separately.

The higher total antioxidant capacity in caries active children as found in this study can be attributed to elevated protein levels. It has been suggested that saliva is rich in antioxidant, mainly uric acid with lesser but definite contributions from albumin, ascorbate and glutathione and all of these are proteins or have proteins in their structure. It has been reported that uric acid is the major antioxidant in saliva accounting for more than $85 \%$ of total antioxidant capacity of both unstimulated and stimulated saliva [15] thus it can be concluded that salivary antioxidant levels must be in a linear association with total protein levels.Our results were in sync with a related study conducted by Tulunoglu which also reported that total antioxidant capacity of saliva increased with caries activity [16]. In our study total antioxidant capacity is decreased in caries free children. It has been suggested that the levels of antioxidants could be altered in response to an infection or disease. The absence of an infectious challenge in the form of caries or poor oral hygiene in our control group could be one of the factors for the comparatively decreased levels of total antioxidant capacity of saliva.

Dental caries is a complex and dynamic process where a multitude of factors influence and initiate the progression of disease. One of the most important factor which influences the development of dental caries is saliva. The physicochemical properties of saliva like $\mathrm{pH}$, buffering capacity, salivary flow rate, concentration of various components like proteins, calcium and antioxidant defense system play a major role in the development of caries.
Within the precincts of this study it was established that total antioxidant capacity of saliva has a linear relation with caries, i.e., as the severity of caries increased, the TAC levels also increase. But in order to extrapolate these findings, studies using larger sample size are needed.

\section{References}

1. Mc-Donald RE, Avery DR, Stookey GK. Dental caries in the child and adolescents. In: Mc-Donald RE, Avery DR, Dean JA, editors. Dentistry for the child and adolescent. 8th ed. New Delhi: Elsevier; 2005. p. 203-35.

2. Shafer WG, Hine MK, Levy BM, editors. A text book of oral pathology, 5th ed. Philadelphia: W. B. Saunders Company; 1993. p. $567-658$.

3. Lavelle CLB. Applied oral physiology, 2nd ed. London: Butterworths and Co (publishers) Ltd; 1988. p. 128-141.

4. John T, Mc Devitt. Saliva as the next best diagnostic tool. J Biochem. 2006;45(2):23-5.

5. Battino M, Ferreior MS, Gallardo I, Newman HN, Bullon P. The antioxidant capacity of saliva. J Clin Periodontol. 2002;29: 189-94.

6. Gopinath VK, Arzreanne. Saliva as a diagnostic tool for assessment of dental caries. Arch Orofac Sci. 2006;1:57-9.

7. Dawes C. Physiological factors affecting salivary flow rate, oral sugar clearance and the sensation of dry mouth in man. J Dent Res. 1987;66(Spec Iss):648-53.

8. Edgar WM. Saliva: its secretion, composition and functions. $\mathrm{Br}$ Dent J. 1992;172:305-10.

9. Amerongen AVN, Bolscher JGM, Veerman ECI. Salivary proteins: protective and diagnostic value in cariology. Caries Res. 2004;38:247-53.

10. Kedjarune U, Migasena $\mathrm{P}$, Changbumrung S, Pongpaew $\mathrm{P}$, Tungtrongchitr R. Flow rate and composition of whole saliva in children from rural and urban Thailand with different caries prevalence and dietary intake. Caries Res. 1997;31:148-54.

11. Lenander-Lumikari M, Loimaranta V. Saliva and dental caries. Adv Dent Res. 2000;14:40-7.

12. Mandel ID. The functions of saliva. J Dent Res. 1987;66(spec iss):623-62.

13. Johansson I, Lenander-Lumikari M, Saellstrom A. Saliva composition in Indian children with chronic protein-energy malnutrition. J Dent Res. 1994;73(1):11-9.

14. Prior RL, Coa G. In vivo total antioxidant capacity: comparison of different analytical methods. Free Radic Biol Med. 1999;27:1173-81.

15. Moore S, Calder KA, Miller NJ, Rice Evans CA. Antioxidant activity of saliva and periodontal disease. Free Radic Res. 1997;26:209-34.

16. Tulunoglu O, Demirtas S, Tulunoglu I. Total antioxidant levels of saliva in children related to caries, age and gender. Int $\mathrm{J}$ Paed Dent. 2006;16:186-91. 